\title{
Seimbangkan Game Online dengan Game Offline \\ di Era Revolusi Industri 4.0
}

\author{
Husniah Ramadhani Pulungan \\ Universitas Muhammadiyah Tapanuli Selatan \\ e-mail: husniah.ramadhani@um-tapsel.ac.id
}

\begin{abstract}
This article aims to strike a balance between online games that have some negative impacts and offline games (which are paired with the term sports or games) in the era of the industrial revolution 4.0, using qualitative descriptive methods with case studies because the data sources are from the utilities of the Angkola originating from a written document titled "Batak Angkola cultural traditions trace the passage of time". The results revealed three categories of utiutan namely: children's games, dexterity, and a means of blocking. Thus, this study can still be developed in further research by deepening the comparison of the types of online games that continue to develop which are equivalent to the types of offline games based on deeper arguments.
\end{abstract}

Keywords: online game; offline game; Sports; Islam; impact

\begin{abstract}
Abstrak
Artikel ini bertujuan untuk mengupayakan penyeimbangan antara game online yang memiliki beberapa dampak negatif dengan game offline (yang dipadankan dengan istilah olahraga atau permainan) di era revolusi industri $4.0 \mathrm{ini}$, dengan menggunakan metode deskriptif kualitatif dengan studi kasus karena sumber datanya dari uti-utian suku Angkola yang berasal dari dokumen tertulis yang berjudul "Adat budaya Batak Angkola menelusuri perjalanan masa". Hasil penelitian mengungkapkan tiga kategori uti-utian yaitu: permainan anak-anak, ketangkasan, dan alat penghalau. Dengan demikian, kajian ini masih dapat dikembangkan dalam penelitian selanjutnya dengan memperdalam perbandingan jenis game online yang terus berkembang yang setara dengan jenis game offline yang dilandasi dengan dalil-dalil yang lebih mendalam.
\end{abstract}

Kata Kunci: game online; game offline; olahraga; Islam; dampak 


\section{Pendahuluan}

Game online sudah mengikis keberadaan game offline di era revolusi industri 4.0 yang sudah terdigitalisasi dewasa ini. Hal ini telah memberikan dampak yang besar bagi masyarakat (dalam hal ini bagi generasi muslim milenial khususnya). Dampak dari game online yang dimaksud dapat dikategorikan menjadi dampak positif dan dampak negatif. Adapun dampak positif yang muncul di antaranya: meningkatkan kerja otak, mengajarkan sportivitas, mengasah kemampuan multi-tasking, bahkan melatih cara kerja tim¹. Sementara itu, dampak negatif yang muncul meliputi telah terjadinya beberapa kasus, di antaranya: sepuluh anak di Banyumas mengalami gangguan mental akibat kecanduan bermain game online sepanjang tahun 2018. Anak-anak tersebut meliputi tujuh dari sepuluh anak merupakan siswa Sekolah Dasar (SD) dan Sekolah Menengah Pertama (SMP). Para anak tersebut sudah tidak dapat mengendalikan diri dalam bermain game online, tidak bisa beraktivitas normal, memicu tindakan dekstruktif, gangguan mental yang memicu obsesif seseorang akibat terlalu banyak berinteraksi dengan dunia virtual. Mereka sekarang dirawat di RSUD dengan pemberian obat penenang agar tidak agresif dan diajak untuk menjajal beragam permainan anak-anak. ${ }^{2}$

Kontradiksi dari dampak positif dan dampak negatif dari game online di atas tentu telah menimbulkan keprihatinan tersendiri. Hal ini juga tidak luput dari perhatian para ilmuwan yang telah berupaya mengkaji dan menganalisis hal-hal yang terkait dengan game online ini. Sebut saja beberapa kajian dari tahun 2018 hingga tahun 2019 belakangan ini

1Teknologi.id, “Inilah 4 Dampak Positif Bermain Game Online,” PT. Teknologi ID Indonesia, 2019, https://teknologi.id/publik/inilah-4-dampak-positif-bermain-game-online/.

${ }^{2}$ Abdul Azis, "Kecanduan Game Online, 10 Anak Di Banyumas Alami Gangguan Mental," Merdeka>Peristiwa, 2018, https://www.merdeka.com/peristiwa/kecanduan-gameonline-10-anak-di-banyumas-alami-gangguan-mental.html. 
Husniah Ramadhani Pulungan

ditemukan kajian yang dimulai dari struktur otak yang terkait dengan kecenderungan kecanduan internet pada pemain game online remaja3; menghindari kecanduan game online di kalangan anak muda4; kecanduan game online di kalangan remaja Turki: efek gaya pengasuhan internet5; dampak permainan online pada perubahan karakter anak-anak6; hingga pada dampak game online mobile legends: bang bang terhadap mahasiswa7.

Berdasarkan berbagai macam kajian yang terkait dengan game online dari berbagai sudut pandang dari berbagai bidang tersebut, pengaruhnya, dampaknya, keuntungannya, resikonya, bahkan usia penggunanya di atas telah memberikan gap penelitian pada artikel ini. Gap penelitian yang dimaksud adalah masih terbatasnya kajian yang menganalisis solusi atau alternatif lain dari kecanduan game online ini.

${ }^{3}$ Nannan Pan et al., "Brain Structures Associated with Internet Addiction Tendency in Adolescent Online Game Players," Frontiers in Psychiatry 9, no. March (2018), hlm. 18, https://doi.org/10.3389/fpsyt.2018.00067.

4Muhammad Guntur Aji Purnama, Oktavia Trian Azizah, and Syam Ja'faros Asshadiq, "Avoiding Online Game Addiction among Youngsters," Bulletin of Social Informatics Theory and Application Vol. 2, No. 1 (2018), hlm. 34-38, https://doi.org/DOI https://doi.org/10.31763/businta.v2i1.104.

5Hasan Özgür, "Online Game Addiction Among Turkish Adolescents: The Effect of Internet Parenting Style," Mojet Malaysian Online Journal of Educational Technology Vol. 7, No. 1 (2019), hlm. 47-68, https://doi.org/DOI Number 10.17220/mojet.2019.01.004.

${ }^{6}$ Gek Diah Sentana Sentana, I Wayan Nerta, and I Gede Suwindia, "The Impact of Online Game on The Children's Character Change," Jurnal Penjaminan Mutu Lembaga Penjaminan Mutu Institut Hindu Dharma Negeri Denpasar Vol. 5, No. 2 (2019), hlm. 13843, https://doi.org/DOI: http://dx.doi.org/10.25078/jpm.v5i2.1088.

${ }^{7}$ Devita Rani, Effiati Juliana Hasibuan, and Rehia K Isabela Barus, "Dampak Game Online Mobile Legends: Bang Bang Terhadap Mahasiswa," PERSPEKTIF Vol. 7, No. 1 (2019), hlm. $\quad$ 6-12, https://doi.org/DOI: http://dx.doi.org/10.31289/perspektif.v7i1.2520. 
Seimbangkan Game Online dengan Game Offline....

Dengan demikian, sesuai dengan keadaan tersebut, maka artikel kali ini akan mencoba memunculkan tiga rumusan masalah yang ingin digali, yaitu: (1) Apa landasan dari game offline? (2) Bagaimana wujud dan makna dari game offline? (3) Bagaimana tema budaya dari game offline.

Selanjutnya, tujuan dari artikel ini untuk mengungkapkan landasan dari game offline, wujudnya, serta tema budaya yang dapat dideskripsikan. Sementara itu, manfaatnya adalah guna menambah kerangka teoretis dalam pemahaman game baik offline maupun online dan juga guna memberikan pandangan pemikiran bagi pembaca agar berupaya untuk menyeimbangkan hidupnya dengan kegiatan yang lebih positif dengan melibatkan olah tubuh (dalam hal ini game offline). Hal ini sesuai dengan pernyataan "Di dalam tubuh yang sehat terdapat jiwa yang kuat". Setidaknya, hal ini merupakan suatu upaya untuk menghindari kecanduan game online dan menjaga kesehatan fisik seseorang yang ingin berubah untuk hidup lebih baik lagi dalam memanajemen gaya hidupnya.

\section{Metode penelitian}

Metode penelitian yang digunakan adalah deskriptif kualitatif. Sumber datanya dari dokumen tertulis dari buku "Adat budaya Batak Angkola menelusuri perjalanan masa". Datanya adalah memunculkan game offline (yang dipadankan dengan istilah olahraga dan permainan) dari suku Angkola selaku bagian dari kearifan lokal (studi kasus). Analisisnya berupa pemaparan game offline dan implementasinya pada masyarakat. Penyajian deskripsi game offline ini akan dikemukakan secara deskriptif dan argumentatif. 
Husniah Ramadhani Pulungan

\section{Hasil dan pembahasan}

Hasil dan pembahasan dari artikel ini dibagi ke dalam tiga subjudul yang terdiri dari: (1) landasan dari game offline, (2) wujud dan makna dari game offline, dan (3) tema budaya dari game offline. Berikut pemaparannya.

\section{(1) Landasan dari game offline}

Game offline adalah permainan yang tidak dilakukan dengan jaringan internet. Apabila dianalisis secara istilah, maka game memiliki tiga pengertian, yaitu: (1) game is an activity or sport usually involving skill, knowledge, or chance, in which you follow fixed rules and try to win against an opponent or to solve a puzzle; (2) game is one particular occasion on which a game is played; (3) game is a part of a match, for example in tennis or bridge, consisting of a fixed number of points ${ }^{8}$. Selanjutnya, istilah offline memiliki dua pengertian, yaitu: (1) not on a regular route of a transportation system; (2) not connected to a computer network ${ }^{9}$. Dengan demikian, game offline bermakna permainan yang melibatkan fisik dan menyehatkan (selanjutnya dipadankan menjadi istilah olahraga ataupun permainan). Olahraga atau permainan ini sudah dikenalkan sejak dulu kala. Bahkan agama pun menganjurkannya, seperti pada pemaparan berikut.

Terkait dengan landasan yang berhubungan dengan olahraga atau permainan tersebut di atas di antaranya ditemukan dalam hadis Bukhari yang artinya: "Mukmin yang kuat lebih baik dan lebih disukai oleh Allah swt.

8Collins Dictionary, “Game," u-dictionary.com, 2019, http://www.udictionary.com/home/word/game/from/en/to/en.

9Collins Dictionary, "Off Line," u-dictionary.com, 2019, http://www.udictionary.com/home/word/off line/from/en/to/en. 
Seimbangkan Game Online dengan Game Offline....

daripada mukmin lemah. ${ }^{10 "}$ Hal ini menguatkan bahwa mukmin yang kuat memiliki fisik yang kuat dan fisik yang kuat dapat diupayakan melalui kegiatan olahraga. Selain itu, didukung oleh hadis Abu Hamid al-Ghazali (w 1111 M/555 H) yang artinya: "Setelah belajar, anak harus diizinkan berolahraga agar tidak bosan, melarang berolahraga dan memaksakan terus belajar hanya akan mematikan hati dan mengikis kecerdasan ${ }^{11 . "}$ Hadis inilah yang semakin mendorong penulis untuk membuat artikel ini demi salah satu upaya penyelamatan generasi dari dampak negatif game online yang kurang baik manajemen pemakaiannya oleh penggunanya sendiri.

Selain itu, menurut ALODOKTER ${ }^{12}$, olahraga dapat menjadi salah satu pemicu utama pengeluaran hormon endorfin, selain dari makanan. Hal ini karena endorfin merupakan zat kimia seperti morfin yang dapat dihasilkan secara alami oleh tubuh dan memiliki peran dalam membantu mengurangi rasa sakit saat yang memicu perasaan positif. Hormon endorfin diproduksi oleh kelenjar pituari dan sistem saraf pusat manusia. Dengan demikian, hormon endorfin yang diperoleh dari berolahraga tadi merupakan cara yang efektif untuk mengobati depresi atau stress, baik depresi dengan tingkat ringan maupun depresi tingkat sedang. Selain itu, olahraga juga dapat membantu seseorang dalam mengatasi perasaan gelisah, meningkatkan kualitas tidur, dan meningkatkan kepercayaan diri.

10Fuji Pratiwi, “Urgensi Olahraga Dalam Pandangan Islam," Republika.co.id (Khazanah), 2017, https://www.republika.co.id/berita/dunia-islam/islamdigest/17/05/31/oqtegt313-urgensi-olahraga-dalam-pandangan-islam.

${ }^{11}$ Fuji Pratiwi.

${ }^{12}$ Allert Benedicto leuan Noya, "Hormon Endorfin: Penghilang Stres Dan Pereda Rasa Sakit Alami," ALODOKTER, 2018, https://www.alodokter.com/hormon-endorfinpenghilang-stres-dan-pereda-rasa-sakit-alami. 
Husniah Ramadhani Pulungan

Berdasarkan pemaparan tersebut di atas, maka landasan untuk menggalakkan kembali game offline selaku padanan dari olahraga atau permainan adalah penting dan perlu untuk dilakukan. Sejarah menunjukkan bahwa olahraga dapat memberikan dampak positif pada kesehatan, memberikan kebugaran tubuh, kejernihan dalam berpikir, kebahagiaan karena mengeluarkan hormone endorfin sebagai hormon bahagia, dan juga prestasi yang melatih sikap sportif dalam menjalani berbagai problema kehidupan.

\section{(2) Wujud dan makna dari game offline}

Salah satu upaya pengenalan game offline (yang telah dipandankan dengan istilah olahraga atau permainan) dapat dikemukakan dari olahraga atau permainan yang dimiliki oleh salah satu suku di Indonesia. Kali ini diadaptasi dari suku Angkola dalam buku "Adat budaya Batak Angkola menelusuri perjalanan masa"13 sebagai salah satu upaya pemertahanan kearifan lokal dan juga penguatan kembali keberadaan olahraga atau permainan di era revolusi industri 4.0. Mengapa suku Angkola? Karena dalam suku ini masih berusaha mempertahankan olahraga ataupun permainan tradisional dalam kehidupannya sehari-hari yang dapat dijadikan sebagai tambahan wawasan dalam berbudaya. Berikut pemaparannya.

Sebelumnya, seni olahraga dalam adat Batak Angkola disebut dengan uti-utian. Seni olah raga ini ada yang merupakan permainan saja dan ada yang merupakan alat senjata yang dapat dipergunakan dalam usaha penghidupan. Kemudian, olah raga ini ada yang untuk anak-anak dan ada pula yang untuk orang dewasa atau orangtua. Semua jenis olah

13Tinggi Barani, Sutan \& Hasibuan, Adat Budaya Batak Angkola Menelusuri Perjalanan Masa. 
Seimbangkan Game Online dengan Game Offline.... raga ini berfungsi untuk membentuk keterampilan para pemainnya. Hal ini akan dijelaskan satu-satu per satu sebagai berikut.

Tabel 1. Permainan Anak-anak

\begin{tabular}{|l|l|l|}
\hline No. & Nama Permainan & \multicolumn{1}{|c|}{ Makna } \\
\hline 1 & Marsimonjap & $\begin{array}{l}\text { Seorang anak berlindung dan bersembunyi, } \\
\text { sedang seorang lagi menutup mata selama } \\
\text { yang bersembunyi mencari tempat } \\
\text { perlindungannya. Permainan ini biasanya } \\
\text { dilakukan di malam hari. }\end{array}$ \\
\hline 2 & Marsibuni & $\begin{array}{l}\text { Permainan anak-anak yang masing-masing } \\
\text { menyembunyikan sesuatu ke dalam tanah } \\
\text { kemudian menutupnya dengan rapi. } \\
\text { Selanjutnya, kawan lainnya mencari apa } \\
\text { yang disembunyikan oleh kawannya } \\
\text { tersebut. }\end{array}$ \\
\hline 3 & Marpoci/Marlajo & $\begin{array}{l}\text { Permainan dengan memainkan biji kemiri } \\
\text { yang disusun berbaris atau ditumpuk. } \\
\text { Jumlah biji kemiri yang kena merupakan } \\
\text { hasil bagi yang menembak /melempar / } \\
\text { membidik. }\end{array}$ \\
\hline 4 & Marcungkil & $\begin{array}{l}\text { Permainan dengan dua potong kayu } \\
\text { sebesar jari dan sebuah lobang tempat } \\
\text { menyungkil anak } \\
\text { cungkil. Kepandaian pemain dalam } \\
\text { menangkap dan mempermainkan anak } \\
\text { cungkil adalah hasil dari yang memainkan } \\
\text { cungkil. }\end{array}$ \\
\hline
\end{tabular}


Husniah Ramadhani Pulungan

\begin{tabular}{|l|l|l|}
\hline No. & Nama Permainan & \multicolumn{1}{|c|}{ Makna } \\
\hline 5 & Marcongke & $\begin{array}{l}\text { Permainan yang membuat lobang pada kayu } \\
\text { berbentuk sampan atau pada tanah. Lobang } \\
\text { diisi dengan sejumlah biji batu dan lobang } \\
\text { tidak boleh kosong. }\end{array}$ \\
\hline 6 & Marbabiat & $\begin{array}{l}\text { Permainan yang membuat garis-garis } \\
\text { dengan jalur-jalur dan bagian-bagian } \\
\text { tertentu dengan mempergunakan beberapa } \\
\text { biji batu kecil atau lidi yang dipotong-potong. }\end{array}$ \\
\hline 7 & $\begin{array}{l}\text { Marpice/markalas- } \\
\text { kalas }\end{array}$ & $\begin{array}{l}\text { Permainan yang membuat garis petak pada } \\
\text { tanah dengan memakai batu gepeng atau } \\
\text { pecahan piring sebagai pelempar petak atau } \\
\text { tingkat kelas. Selanjutnya, pemain } \\
\text { membentuk lentikan pinggang dengan } \\
\text { membalikkan badan ke belakang lalu kepala } \\
\text { ke bawah melengkung. }\end{array}$ \\
\hline 8 & Margala/marsiolat & $\begin{array}{l}\text { Permainan yang membuat beberapa } \\
\text { gawang yang tiap gawang dijaga oleh satu } \\
\text { orang. Kemudian, pemain yang lain } \\
\text { mencoba menembus gawang tersebut agar } \\
\text { dapat melewati gawang dan tidak } \\
\text { tertangkap. }\end{array}$ \\
\hline 9 & Sidingkat atau main \\
tali & $\begin{array}{l}\text { Permainan dengan merentangkan tali yang } \\
\text { diputar dua orang atau beberapa orang } \\
\text { lainnya melompat dan jangan sampai kena } \\
\text { tali. Bila kakinya kena tali berarti batal dan } \\
\text { menjadi tukang pusing tali. }\end{array}$ \\
\hline
\end{tabular}


Seimbangkan Game Online dengan Game Offline....

\begin{tabular}{|l|l|l|}
\hline No. & Nama Permainan & \multicolumn{1}{|c|}{ Makna } \\
\hline 10 & Marsiayak & $\begin{array}{l}\text { Permainan yang mengejar kawan. Apabila } \\
\text { kawan yang dikejar tertangkap maka yang } \\
\text { kawan yang tertangkap tersebut bertugas } \\
\text { menjadi pengejar. }\end{array}$ \\
\hline 11 & Panca & $\begin{array}{l}\text { Adu tangan jari, telapak tangan, dan lengan. } \\
\text { Kemudian, siapa yang rebah lengannya } \\
\text { duluan dialah yang kalah dalam permainan } \\
\text { ini. }\end{array}$ \\
\hline
\end{tabular}

Berdasarkan tabel 1 di atas maka dapat dijelaskan bahwa permainan yang dilakukan oleh anak-anak dari suku Angkola keseluruhannya menggunakan fisik. Anak-anak berlari, melompat, bersembunyi, adu kekuatan, mencungkil, dan bahkan adu kecerdikan dengan mengatur strategi menghadapi lawan. Permainan anak-anak ini dapat melatih kecerdasan emosional mereka dalam bermain, belajar menghargai kemenangan, berlapang dada menerima kekalahan, bahkan mereka menjadi sehat dan bugar karena sudah bergembira dan berolahraga dengan teman-temannya. Selain itu, terdapat juga beberapa ketangkasan yang dapat dilihat pada tabel 2 berikut.

Tabel 2. Beberapa Ketangkasan

\begin{tabular}{|l|l|l|}
\hline No & \multicolumn{1}{|c|}{ Ketangkasan } & \multicolumn{1}{|c|}{ Makna } \\
\hline 1 & Raga & $\begin{array}{l}\text { Beberapa orang anak main melingkar, } \\
\text { menyepak bola rotan ke atas (bulat seperti } \\
\text { bola). }\end{array}$ \\
\hline 2 & $\mathrm{Bal}$ & $\begin{array}{l}\text { Main bola yang alatnya dari bola kulit dan } \\
\text { bagi anak-anak ada yang mempergunakan }\end{array}$ \\
\hline
\end{tabular}




\begin{tabular}{|c|c|c|}
\hline No & Ketangkasan & Makna \\
\hline & & $\begin{array}{l}\text { jeruk besar yang mentah (unte godang) } \\
\text { sebagai bolanya. }\end{array}$ \\
\hline 3 & $\begin{array}{l}\text { Ultop atau panah } \\
\text { tiup }\end{array}$ & $\begin{array}{l}\text { Permainan menembak dengan sumpit dari } \\
\text { bambu dan anaknya dibuat dari lidi atau } \\
\text { kawat yang runcing bagian ujung dan tumpul } \\
\text { bagian belakang. }\end{array}$ \\
\hline 4 & Sior atau panah & $\begin{array}{l}\text { Permainan yang alatnya dibuat dari sebilah } \\
\text { bambu atau rotan yang mempunyai anak } \\
\text { panah sebagai peluru. }\end{array}$ \\
\hline 5 & $\begin{array}{l}\text { Ambalang atau } \\
\text { seuntai kulit kayu }\end{array}$ & $\begin{array}{l}\text { Permainan yang mempunyai penampungan } \\
\text { batu besar sebagai anak ambalang atau } \\
\text { peluru. Hal ini berguna untuk melempar. }\end{array}$ \\
\hline 6 & Katapel & $\begin{array}{l}\text { Panah karet ban sebesar jari yang } \\
\text { menggunakan cabang kayu dan kulit } \\
\text { sebagai tempat peluru dari batu yang } \\
\text { sebesar induk jari tangan. }\end{array}$ \\
\hline
\end{tabular}

Tabel 2 di atas mengemukakan bahwa ketangkasan dapat dilatih dengan alat-alat sederhana yang ditemukan di alam sekitar. Tidak perlu mahal, tidak mengapa jika bentuknya tradisional. Namun, bahan yang terbuat dari rotan, jeruk besar, lidi, kawat, bambu, cabang kayu, dan kulit dapat menghasilkan ketangkasan yang baik bagi penggunanya. Kemudian, terdapat juga beberapa alat penghalau untuk berburu dan menjaga tanaman seperti pada tabel 3 berikut. 
Seimbangkan Game Online dengan Game Offline....

Tabel 3. Beberapa alat penghalau untuk berburu dan menjaga tanaman

\begin{tabular}{|l|l|l|}
\hline No. & Alat Penghalau & \multicolumn{1}{|c|}{ Makna } \\
\hline 1 & Marsambat & $\begin{array}{l}\text { Membuat lingkaran tali yang dapat mengikat } \\
\text { kaki binatang yang melewati. }\end{array}$ \\
\hline 2 & Marsambil & $\begin{array}{l}\text { Membuat lingkaran tali yang pakai alat } \\
\text { penarik bila tersentuh oleh binatang hingga } \\
\text { terjerat. }\end{array}$ \\
\hline 3 & Martinjak & $\begin{array}{l}\text { Biasanya untuk menangkap binatang yang } \\
\text { besar, seperti: rusa, kijang, dan lain-lain. }\end{array}$ \\
\hline 4 & Pilubang & $\begin{array}{l}\text { Membuat lobang besar dan ditutup dari atas. } \\
\text { Hal ini tujuannya agar binatang yang lewat di } \\
\text { atasnya jatuh ke dalam lobang. }\end{array}$ \\
\hline 5 & Turangkap & $\begin{array}{l}\text { Alat untuk menangkap binatang buas seperti } \\
\text { harimau dan lainnya yang dibuat dari kayu } \\
\text { yang kuat sebagai pagar dan pakai pintu } \\
\text { yang pakai alat penggerak untuk menutup } \\
\text { pintu. Seandainya binatang masuk dengan } \\
\text { sendirinya tidak bisa keluar dari dalam. } \\
\text { Namun, untuk burung ada yang dibuat dari } \\
\text { pohon sanggaryang disebut dengan binjora. }\end{array}$ \\
\hline 6 & Basir & $\begin{array}{l}\text { Bambu teras yang runcing seperti tombak } \\
\text { yang tertancap pada lobang lintasan } \\
\text { binatang. Apabila lobang itu terpijak oleh } \\
\text { binatang dan terjatuh ke dalamnya maka } \\
\text { binatang itu akan terluka dan kemungkinan } \\
\text { akan mati. }\end{array}$ \\
\hline $\begin{array}{l}\text { Sejenis alat penjepit yang dibuat dari besi } \\
\text { untuk menangkap binatang buas yang }\end{array}$ \\
\hline 5
\end{tabular}


Husniah Ramadhani Pulungan

\begin{tabular}{|c|c|c|}
\hline No. & Alat Penghalau & Makna \\
\hline & & $\begin{array}{l}\text { diletakkan pada binatang bekas } \\
\text { penerkamannya yang sudah mati. }\end{array}$ \\
\hline 8 & Pulut & $\begin{array}{l}\text { Alat untuk menangkap burung yang dibuat } \\
\text { pada kayu yang beranting getah-getah yang } \\
\text { dapat merekat burung apabila dihinggapi } \\
\text { burung tersebut. Biasanya diletakkan pada } \\
\text { linkungan yang sedang dijaga (padi). }\end{array}$ \\
\hline 9 & Hail atau pancing & Alat penangkap ikan. \\
\hline 10 & Sambotik & Sejenis alat pancing juga. \\
\hline 11 & Sasir & $\begin{array}{l}\text { Alat dengan memasang teratak bambu di } \\
\text { permukaan air. }\end{array}$ \\
\hline 12 & Durung & $\begin{array}{l}\text { Sebentuk tanggul dari kulit kayu yang } \\
\text { didandan atau dijalin pada bingkai dari rotan } \\
\text { besar. }\end{array}$ \\
\hline 13 & Luka atau bubu & $\begin{array}{l}\text { Alat untuk menangkap ikan dari terugi enau } \\
\text { yang berbentuk kerangka. Bubu terbuat dari } \\
\text { bambu dan lebih besar dari luka. }\end{array}$ \\
\hline 14 & Mangarsik & $\begin{array}{l}\text { Menangkap ikan dengan mengeringkan air } \\
\text { atau anak sungai. }\end{array}$ \\
\hline 15 & Marsulu & $\begin{array}{l}\text { Alat menangkap ikan dengan membawa } \\
\text { obor. }\end{array}$ \\
\hline 16 & Manohan & $\begin{array}{l}\text { Alat-alat menangkap ikan dengan } \\
\text { menaburkan air tuba ke dalam air. }\end{array}$ \\
\hline 17 & Manuba & $\begin{array}{l}\text { Menangkap ikan dengan menaburkan air } \\
\text { tuba ke dalam air. }\end{array}$ \\
\hline 18 & Manjala & Menangkap ikan dengan rambang atau jala. \\
\hline
\end{tabular}


Seimbangkan Game Online dengan Game Offline....

\begin{tabular}{|c|c|c|}
\hline No. & Alat Penghalau & Makna \\
\hline 19 & Alaan & $\begin{array}{l}\text { Membuat suatu kolam di bagian-bagian } \\
\text { sungai dengan membendung dengan batu- } \\
\text { batuan ke dalam bendungan ini. Kemudian, } \\
\text { setelah nampak banyak ikan baru } \\
\text { dikeringkan dan ikannya diambil. }\end{array}$ \\
\hline 20 & Martanggul & $\begin{array}{l}\text { Menangkap ikan dengan tanggul yaitu } \\
\text { sebentuk rambang yang pakai tangan } \\
\text { pegangan. }\end{array}$ \\
\hline 21 & Hupak & $\begin{array}{l}\text { Alat untuk mengetahui masuknya babi ke } \\
\text { dalam tanaman pada malam hari yang } \\
\text { direntangkan tali di sekeliling tanaman yang } \\
\text { memakai penarik gendang. Bila tali } \\
\text { tersentuh, tali tersentak dan gendang } \\
\text { berbunyi. Pertanda ada binatang masuk ke } \\
\text { dalam tanaman. }\end{array}$ \\
\hline 22 & Hotor & $\begin{array}{l}\text { Serus bambu yang direkah dan ditancapkan } \\
\text { di atas tiang yang berada di tengah } \\
\text { perladangan atau persawahan, dan diikat tali } \\
\text { yang direntangkan sampai ke dangau, } \\
\text { kemudian ditarik-tarik lalu terdengarlah suara } \\
\text { yang dapat menghalau burung. }\end{array}$ \\
\hline 23 & Gumpar & $\begin{array}{l}\text { Selembar seng atau kaleng yang dipakukan } \\
\text { dua buah tiang dan beberapa potong kayu } \\
\text { alat pemukul, yang disusun tergantung pada } \\
\text { sebuah potongan kayu yang memakai tali } \\
\text { untuk disentak-sentak. }\end{array}$ \\
\hline
\end{tabular}


Husniah Ramadhani Pulungan

Berdasarkan tabel 3 di atas maka dapat dikemukakan bahwa semua alat penghalau tersebut merupakan upaya manusia dalam mempertahankan hidupnya dengan mempertahankan hasil tanaman dari gangguan hewan. Kemudian, terdapat juga beberapa alat untuk menangkap hewan buruan dan terdapat juga beberapa alat untuk menangkap ikan. Keseluruhan aktivitas tersebut menggunakan fisik dan ketangkasan yang otomatis juga sudah termasuk bagian dari olahraga yang membugarkan tubuh.

\section{(3) Tema budaya dari game offline}

Tema budaya dari game offline (olahraga atau permainan) dari suku Angkola yang telah dideskripsikan sebelumnya akan diungkapkan seperti pada tabel 4 berikut.

Tabel 4. Tema Budaya dari Game Offline (Olahraga atau Permainan) dari Suku Angkola

\begin{tabular}{|l|l|l|l|}
\hline No. & \multicolumn{2}{|c|}{ Tema Budaya } & \multicolumn{1}{c|}{$\sum$} \\
\hline 1 & Permainan anak-anak & 11 & $27,5 \%$ \\
\hline 2 & Ketangkasan & 6 & $15 \%$ \\
\hline 3 & Alat Penghalau & 23 & $57,5 \%$ \\
\hline \multicolumn{2}{|c|}{ Jumlah } & 40 & $100 \%$ \\
\hline
\end{tabular}

Tabel 4 di atas memunculkan bahwa yang tertinggi adalah alat penghalau sebanyak 23 dengan 57,5\%. Hal ini menunjukkan bahwa aktivitas fisik lebih banyak untuk digunakan dalam bekerja baik dalam berburu ataupun bercocok tanam sehingga menghasilkan beragam alat penghalau yang kreatif dan inovatif dalam penggunaannya. Selanjutnya, permainan anak-anak yang muncul sebanyak 11 permainan dengan 
Seimbangkan Game Online dengan Game Offline....

$27,5 \%$. Hal ini mengungkapkan bahwa alternatif permainan bagi anak-anak masih cukup banyak sehingga anak-anak dapat memainkan permainan yang mana saja dengan riang gembira. Tentunya tanpa disadari membuat anak-anak menjadi lebih sehat dan bugar akibat aktivitas yang beragam tadi. Terakhir adalah ketangkasan sebanyak 6 dengan persentase $15 \%$. Hal ini karena ketangkasan merupakan permainan yang lebih membutuhkan konsentrasi yang lebih serius dibandingkan dengan yang lainnya. Sebab di antara ketangkasan itu terdapat menembak, menyumpit, dan sebagainya yang membutuhkan fokus yang lebih terlatih.

Sesuai dengan seluruh penjelasan di atas, maka dapat disimpulkan bahwa game online disarankan untuk diseimbangkan dengan game offline (yang dipadankan dengan olahraga atau permainan). Olahraga atau permainan yang diambil dari suku Angkola tersebut dapat melatih kebugaran, ketangkasan, interaksi sosial yang positif (kerja sama, jujur, sportif, solidaritas, kesetiakawanan, toleransi, sabar, gesit, pandai mencari peluang, pandai mencari solusi), belajar menghargai kemenangan, berlapang dada menghadapi kekalahan, berpikiran jernih, dan yang paling penting adalah menjadi bahagia dalam menjalani hidup.

\section{Penutup}

Salah satu upaya untuk menyeimbangkan kecanduan game online adalah dengan mengenalkan kembali game offline (yang dipadankan dengan olahraga atau permainan) di era revolusi industri 4.0. Selain memang dianjurkan dalam agama untuk berolahraga, maka bentuk olahraga yang menjadi bagian dari kearifan lokal juga perlu untuk dipertahankan dan dilestarikan sebelum terjadi pengausan. Pengenalan ini dilakukan dari uti-utian yang dimiliki oleh suku Angkola yang terdiri dari tiga kategori yaitu: permainan anak-anak, ketangkasan, dan alat penghalau. 
Husniah Ramadhani Pulungan

Kecenderungan penggunaan ketiga kategori tersebut dapat memberikan dampak yang positif bagi orang yang menggunakannya. Beberapa dampak positif yang akan diperoleh yaitu: dapat melatih kebugaran, ketangkasan, interaksi sosial yang positif (kerja sama, jujur, sportif, solidaritas, kesetiakawanan, toleransi, sabar, gesit, pandai mencari peluang, pandai mencari solusi), belajar menghargai kemenangan, berlapang dada menghadapi kekalahan, berpikiran jernih, dan yang paling penting adalah menjadi bahagia dalam menjalani hidup.

Tentunya, penelitian ini juga masih memiliki celah untuk dikaji lebih lanjut, misalnya pada perbandingan antara jenis game online yang satu dengan jenis game online yang lain beserta dampaknya bagi penggunanya. Hal ini juga dapat ditinjau dari segi ilmu agama dengan mengurai kembali dalil-dalil yang lebih lengkap baik dari Alquran dan Hadis yang shahih dan dikaitkan dengan sejarah Nabi Muhammad saw. dengan para sahabatnya dalam berolahraga.

\section{Daftar pustaka}

Azis, Abdul. "Kecanduan Game Online, 10 Anak Di Banyumas Alami Gangguan Mental.” Merdeka>Peristiwa, 2018. https://www.merdeka.com/peristiwa/kecanduan-game-online-10anak-di-banyumas-alami-gangguan-mental.html.

Collins Dictionary. "Game." u-dictionary.com, 2019. http://www.udictionary.com/home/word/game/from/en/to/en.

—. "Off Line." u-dictionary.com, 2019. http://www.udictionary.com/home/word/off line/from/en/to/en. 
Seimbangkan Game Online dengan Game Offline.... dr. Allert Benedicto leuan Noya. "Hormon Endorfin: Penghilang Stres Dan Pereda Rasa Sakit Alami." ALODOKTER, 2018. https://www.alodokter.com/hormon-endorfin-penghilang-stres-danpereda-rasa-sakit-alami.

Fuji Pratiwi. "Urgensi Olahraga Dalam Pandangan Islam." Republika.co.id (Khazanah), 2017. https://www.republika.co.id/berita/duniaislam/islam-digest/17/05/31/oqtegt313-urgensi-olahraga-dalampandangan-islam.

Özgür, Hasan. "Online Game Addiction Among Turkish Adolescents: The Effect of Internet Parenting Style." Mojet Malaysian Online Journal of Educational Technology Vol. 7, No. 1 (2019), hlm. 47-68. https://doi.org/DOI Number 10.17220/mojet.2019.01.004.

Pan, Nannan, Yongxin Yang, Xin Du, Xin Qi, Guijin Du, Yang Zhang, Xiaodong $\mathrm{Li}$, and Quan Zhang. "Brain Structures Associated with Internet Addiction Tendency in Adolescent Online Game Players." Frontiers in Psychiatry Vol. 9, No. March (2018), hlm. 1-8. https://doi.org/10.3389/fpsyt.2018.00067.

Purnama, Muhammad Guntur Aji, Oktavia Trian Azizah, and Syam Ja'faros Asshadiq. "Avoiding Online Game Addiction among Youngsters." Bulletin of Social Informatics Theory and Application Vol. 2, No. 1 (2018), hlm. $\quad 34-38 . \quad$ https://doi.org/DOI https://doi.org/10.31763/businta.v2i1.104.

Rani, Devita, Effiati Juliana Hasibuan, and Rehia K Isabela Barus. 
Husniah Ramadhani Pulungan

"Dampak Game Online Mobile Legends: Bang Bang Terhadap Mahasiswa." PERSPEKTIF Vol. 7, No. 1 (2019), hlm. 6-12. https://doi.org/DOI: http://dx.doi.org/10.31289/perspektif.v7i1.2520.

Sentana, Gek Diah Sentana, I Wayan Nerta, and I Gede Suwindia. "The Impact of Online Game on The Children's Character Change." Jurnal Penjaminan Mutu Lembaga Penjaminan Mutu Institut Hindu Dharma Negeri Denpasar Vol. 5, No. 2 (2019), hlm. 138-43. https://doi.org/DOI: http://dx.doi.org/10.25078/jpm.v5i2.1088.

Teknologi.id. "Inilah 4 Dampak Positif Bermain Game Online." PT. Teknologi ID Indonesia, 2019. https://teknologi.id/publik/inilah-4dampak-positif-bermain-game-online/.

Tinggi Barani, Sutan \& Hasibuan, Zainal Efendi. Adat Budaya Batak Angkola Menelusuri Perjalanan Masa. Medan: Partama Mitra Sari, 2017. 